\title{
Surface Control of Thermosetting Fluorinated Polyurethane
}

\author{
Dongsheng Cai, Yangsheng Ren, Ying $\mathrm{Li}^{*}$, Xia Wang* \\ School of Material Science \& Engineering, University of Shanghai for Science and Technology, Shanghai 200093, P. R. China
}

\begin{abstract}
In this paper, thermosetting fluorine-containing polyurethane (S-FPU) was synthesized through a novel method with two-step process and its surface properties was studied. Firstly, fluorine-containing epoxy compound (FO) was obtained by epichlorohydrin (ECH) and tetrafluoropropanol (TFP). Further, the fluorinated polyether polyols (FPO) was synthesized by cationic copolymerization of tetrahydrofuran (THF) with the FO, the fluorine was located on the side chains of the FPO and the molecular weight of FPO was controllable, besides, the molecular weight distribution of FPO was narrow. Finally, the S-FPU was prepared by FPO as soft segment, MDI as a hard segment and TEA as chain extender. The influence of fluorine enrichment on the surface properties of S-FPU was studied by controlling curing temperature, curing time and structure of FPO. In addition, the surface fluorine content of S-FPU and the surface hydrophobicity were studied in detail. The results showed that with the curing temperature decreased, the surface fluorine content of S-FPU increased, and when the curing time was more than 10 hours, the fluorine element did not migrate to the surface. What's more, with the molecular weight of FPO increased, the surface fluorine content of S-FPU increased.
\end{abstract}

\section{Introduction}

Polyurethanes are used in a wide range of applications, mainly because their properties may be easily tailored to vastly different end results, ranging from stiff, thermoset materials to soft expanded elastomers ${ }^{[1]}$. It has been well-known that fluorine has the strongest electro negativity of all the elements ever known, and its atomic radius is merely larger than that of hydrogen [2-4]. Therefore, its atomic nucleus controls its electrons and electron clouds firmly. There is strong intermolecular force in the polymer containing C-F bond, which imparts remarkable properties including high thermal stability, low surface free energy, good hydrophobicity, good chemical-resistance to polymers and improved solvent and chemical resistance when compared with their analogs without fluorine. It is a good method to complement the disadvantages of PU by introducing fluorine-containing compounds into $\mathrm{PU}{ }^{[5]}$. The properties of fluorinated PU such as a low surface tension, and low coefficient of friction resulting in wide application in the areas of coating, leather decoration, textiles and medicine, especially anticorrosive coatings. So, extensive work has been done on the fluorinated polyurethanes, due to their unique properties ${ }^{[6-10]}$

There are also some problems with the synthesis of fluorinated polyurethane using fluorinated extenders. These extenders, because of their low molecular weights, do not present the improvement of properties ${ }^{[11]}$. Up to now, fluorinated polyurethanes (FPUs) with fluorinated chains in the hard-segment, soft-segment or fluorocarbon end-capped polyurethane has been reported. When fluorine segment in hard segment, the surface fluorine element is very low because of fluorocarbon chains are hindered. For FPU with fluorinated side-chain in the hard segment, fluorine can be enriched on the surface during processing resulting in the high fluorine content on the surface, but the mechanical properties of the material is poor. ${ }^{[12]}$ FPU was mostly synthesized by fluorinated macromolecular as soft segment. Ameduri ${ }^{[13]}$ proposed that the surface properties of fluorinated materials with fluorine-containing pendent groups were better than those with fluorinated groups in the main chains. But the fluorinated polyurethane was seldom synthesized by macromolecular diols as soft segment with fluorine-containing pendent groups. Tao Liu et al. ${ }^{[14]}$ prepared side-chain fluorinated polyether diol with self-made flurorinated glycidyl ether by ring-opening polymerization, and a series of fluorinated thermoplastic polyurethane elastomer, the polyurethane that fluorinated side-chain in the soft-segment were prepared by two-step bulk, but the mechanical property of polyurethane was not high enough. Kim et al. reported that fluorinated polyurethane (PU) was blended with base PU prior to dispersion in water to modify the surface of UV cured WPU. Atomic force microscopy (AFM) showed that the surface was roughened with the addition of fluorinated PU. Jeong et al. modified conventional PU dispersion by

${ }^{a}$ Corresponding author: liying@usst.edu.cn 
blending the base PU and fluorinated urethane oligomer prior to water dispersion. Surface roughness of the cast film increased over 13 times according to AFM tests, and the contact angles with water and methylene iodide were beyond 90 after the addition of $15 \%$ fluorinated urethane oligomer. $^{[15,16]}$

In this work, S-FPU was synthesized and the surface properties of S-FPU was studied in detail. Firstly, FO was prepared by ECH and TFP. Further, the FPO with different molecular weight was synthesized by cationic copolymerization of tetrahydrofuran (THF) with the FO, and the structure of FPO was analyzed by FT-IR, ${ }^{1} \mathrm{H}$ NMR and ${ }^{13} \mathrm{C}$ NMR. Last, the S-FPU was prepared by FPO as soft segment, MDI as a hard segment and TEA as chain extender. The surface fluorine content of S-FPU was determined by X-ray photoelectron spectroscopy (XPS) and the hydrophobic of S-FPU was analyzed by contact angle testing. In addition the effects of curing temperature, curing time and structure of FPO on the surface of the S-FPU were studied.

\section{Experimental Section}

\subsection{Materials}

Tetrafluoropropanol

(TFP)

and

diphenl-methane-diisocyante (MDI) were purchased from sigma(USA).The fluorinated epoxy compound(FO) and the fluorinated polyether polyol(FPO) were prepared according to the literature.

\subsection{Synthesis of fluorinated epoxy compounds (FO) and fluorinated polyether polyol (FPO)}

FO and FPO were prepared according to the reference ${ }^{[16,17]}$.

\subsection{Synthesis of S-FPU}

First, the fluorinated polyether polyol was dehydrated in vacuum under $100{ }^{\circ} \mathrm{C}$ for 2 hours. Then, the calculated FPO was added into a three flask equipped with a mechanical stirrer and use nitrogen as protective gas. Next, the calculated MDI was added into the flask, heat up to $80^{\circ} \mathrm{C}$ and react for 2 hours with stirring. Last, after the reaction, cool down to $40^{\circ} \mathrm{C}$, the calculated TEA was added into the flask, stir fast and transfer polymer to the mould. The curing temperatures ranged from $40{ }^{\circ} \mathrm{C}$ to $100^{\circ} \mathrm{C}$

\section{Results and discussion}

The FT-IR spectra of FO and FPO were shown in Fig.1. For the FO, the stretching vibrations of the $\mathrm{C}-\mathrm{O}$ groups occurred at $1109 \mathrm{~cm}^{-1}$ and $761 \mathrm{~cm}^{-1}$, the stretching vibrations of the methyl groups occurred at $3019 \mathrm{~cm}^{-1}$ and $2941 \mathrm{~cm}^{-1}$, the stretching vibrations of the three-ring groups and the $\mathrm{C}-\mathrm{F}$ groups occurred at $1415 \mathrm{~cm}^{-1}$ and $1210 \mathrm{~cm}^{-1}$ respectively. We could observe that the compound retained the three-ring structure and fluorine was introduced into the epoxide successfully. For the FPO, the stretching vibrations of the $\mathrm{O}-\mathrm{H}$ groups occurred at $3442 \mathrm{~cm}^{-1}$, the stretching vibrations of the $\mathrm{C}-\mathrm{H}$ groups occurred at $2951 \mathrm{~cm}^{-1}$ and $2843 \mathrm{~cm}^{-1}$, the bending vibrations of the $\mathrm{C}-\mathrm{H}$ groups occurred at $1459 \mathrm{~cm}^{-1}$. Above analysis proved that $-\mathrm{OH}$ and $-\mathrm{CH}_{2}$ groups were in the compound. In addition the peaks at $1233 \mathrm{~cm}^{-1}$ and $1370 \mathrm{~cm}^{-1}$ indicated that the compound belonged to a kind of primary alcohol. The fluorine-containing groups was completely consumed in the reaction, which was consistent with the results of the ${ }^{13} \mathrm{C}$ NMR of FPO (Fig.2). It was evident that the peaks appear at $27 \mathrm{ppm}$ and 70 ppm were attributed to THF. Two peaks at $65-80 \mathrm{ppm}$ and 105-120 ppm were relative to the fluorinated epoxy compound. Thus, we concluded that the fluorinated polyether polyol was synthesized by cationic copolymerization of THF with the FO. Besides, the peaks of ${ }^{13} \mathrm{C}$ NMR assigned to the random copolymer of polyether polyol mainly appear at $70-80 \mathrm{ppm}$. This is the same as ${ }^{13} \mathrm{C}$ NMR of the random.
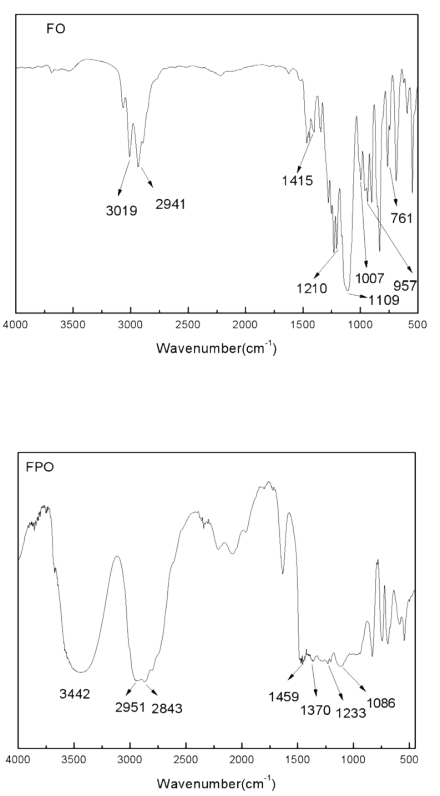

Fig.1 The FT-IR curves of FO and FPO

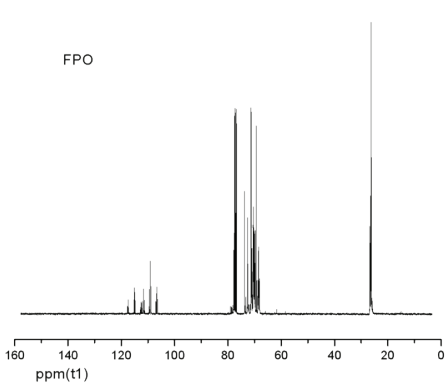

Fig. $2{ }^{13} \mathrm{C}$ NMR curve of FPO 
By controlling the curing temperature, thermosetting fluorinated polyurethane (S-FPU) was synthesized under different curing temperature. The surface element content was measured by XPS. The results were shown in table 1 .

Table 1. The element content of S-FPU with different curing temperature

\begin{tabular}{lccccc}
\hline \multicolumn{1}{c}{ Samples } & Curing temperature & \multicolumn{3}{c}{ Element content $(\mathrm{mol} \%)$} \\
& $\left({ }^{\circ} \mathrm{C}\right)$ & $\mathrm{C}$ & $\mathrm{O}$ & $\mathrm{N}$ & $\mathrm{F}$ \\
\hline S-FPU $_{3}-40-15-1530-1: 2$ & 40 & 61.56 & 26.22 & 3.68 & 8.54 \\
S-FPU $_{3}-60-15-1530-1: 2$ & 60 & 62.41 & 27.76 & 2.95 & 6.88 \\
S-FPU $_{3}-80-15-1530-1: 2$ & 80 & 65.92 & 26.66 & 2.17 & 5.25 \\
S-FPU $_{3}-100-15-1530-1: 2$ & 100 & 64.76 & 29.23 & 1.71 & 4.30 \\
\hline
\end{tabular}

From table1, it was clearly observed that the surface fluorine content decreased with the increase of curing temperature, because that the formation of three-dimensional network structure was easier and faster when the curing temperature increased. The dimensional network would hinder the motion of the fluorine-containing side segments, which leaded to the decrease of surface fluorine content. Therefore, we concluded that lower curing temperature was advantaged for the migration of fluorine element to the surface.

Fig. 3 showed the influence of curing temperature on surface fluorine content of S-FPU. When the curing time was more than $10 \mathrm{~h}$, the surface fluorine content was not changed, because that before the completely formation of three-dimensional network structure, it was easier for the side segments to migrate to the surface, but when the curing time got to a certain degree, it was harder for the fluorine-ontaining side segments to move. Thus, when the curing time was more than $10 \mathrm{~h}$, the three-dimensional network structure formed, so the side segments can't move, which leaded to decrease of surface fluorine.

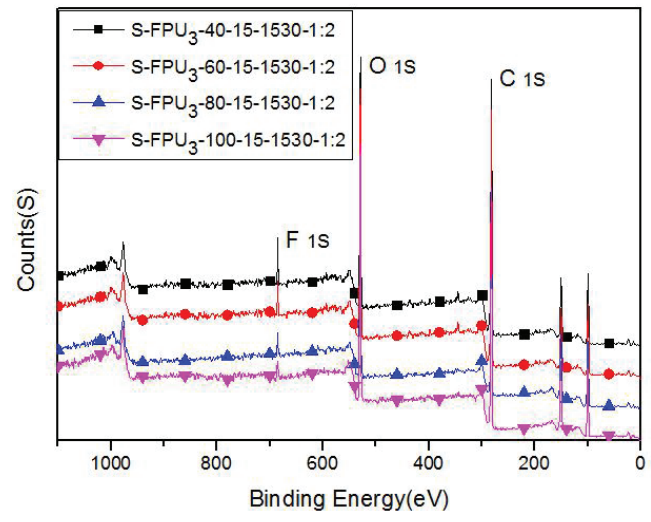

Fig.3 The XPS curves of S-FPU

From table.2, it could be clearly seen that the surface fluorine content of S-FPU $3-1600-1: 2$ was the highest, and the surface fluorine content of S-FPU $\mathrm{H}_{3}-1600-1: 1$ was the least. On one hand, for the S-FPU $3-1600-1: 1$, the distance between fluorine-containing side segments was shorter, so the space steric hindrance was stronger, which hindered the motion of the segments resulting in the decrease of surface fluorine content. When S-FPU was synthesized, at the beginning, the fluorine-containing side chains could move to the surface, after the cross linked network structure formed, the position of the fluorine side chains was fixed. If the distance between fluorinated side chains was shorter, the entanglement between molecular chains would occur more easily, which increased the steric hindrance, so it was harder for the fluorine-containing side chains to move to the surface before the formation of three-dimensional network, which leaded to decrease of surface fluorine content. On the other hand, the noumenal fluorine content of S-FPU3-1600-1:3 was lower than $\mathrm{S}_{-} \mathrm{FPU}_{3}-1600-1: 2$, and the amount of fluorine atom of $\mathrm{S}_{-}-\mathrm{PU}_{3}-1600-1: 3$ that could move to the surface was lower, so the surface fluorine content of S-FPU $3-1600-1: 3$ was lower than S-FPU3-1600-1:2.

Table 2. The element content of S-FPU with different structure of FPO

\begin{tabular}{|c|c|c|c|c|}
\hline \multirow[t]{2}{*}{ Samples } & \multicolumn{4}{|c|}{ Element content $(\mathrm{mol} / \%)$} \\
\hline & $\mathrm{C}$ & $\mathrm{O}$ & $\mathrm{N}$ & $\mathrm{F}$ \\
\hline S-FPU $_{3}-30-10-1600-1: 1$ & 63.85 & 32.36 & 0 & 3.79 \\
\hline $\mathrm{S}_{-\mathrm{FPU}_{3}-30-10-1600-1: 2}$ & 62.41 & 27.76 & 2.95 & 6.88 \\
\hline $\mathrm{S}_{-} \mathrm{FPU}_{3}-30-10-1600-1: 3$ & 63.85 & 26.06 & 3.74 & 6.35 \\
\hline $\begin{array}{l}\text { S-FPU }{ }_{3}-40-15-1530-1: 2 \text {, } \\
\text { S-FPU } 3-80-15-1530-1: 2 \text { and } \\
\text { were synthesized under the } \\
100^{\circ} \mathrm{C} \text {. The Fig } 4 \text { and table } 3 \\
\text { temperature decreased, th } \\
\text { increased. We concluded tha } \\
\text { temperature, surface fluorin } \\
\text { resulting in the decrease } \\
\text { demonstrated that the hydrop } \\
\text { by the surface fluorine conten }\end{array}$ & $\begin{array}{l}\text { S-H } \\
\text { S-F } \\
40 \\
\text { showe } \\
\text { e sur } \\
\text { t with } \\
\text { conte } \\
\text { of co }\end{array}$ & $\begin{array}{l}\mathrm{PU}_{3}-60 \\
\mathrm{U}_{3}-10 \\
, 60{ }^{\circ} \mathrm{C} \\
\text { that } \mathrm{W} \\
\text { ace } \mathrm{c} \\
\text { he incre } \\
\text { it grad }\end{array}$ & $\begin{array}{l}15-15 \\
15-15 \\
, 80 \\
\text { th the } \\
\text { ntact } \\
\text { ase of } \\
\text { ally } r\end{array}$ & $\begin{array}{l}0-1: 2, \\
0-1: 2 \\
\text {,and } \\
\text { uring } \\
\text { angle } \\
\text { uring } \\
\text { duced } \\
\text { which } \\
\text { cided }\end{array}$ \\
\hline
\end{tabular}

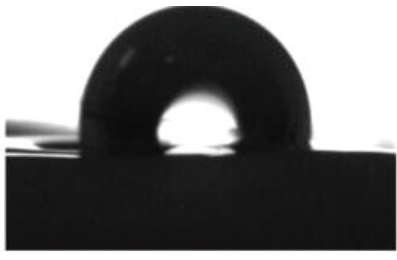

S-FPU $3-40-15-1530-1: 2$

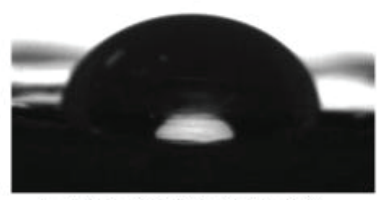

S-FPU $3-80-15-1530-1: 2$

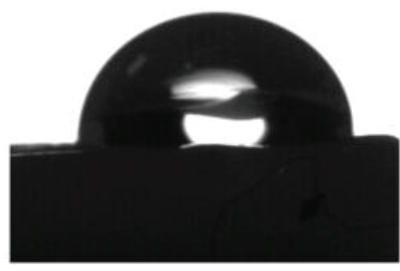

S-FPU $3-60-15-1530-1: 2$

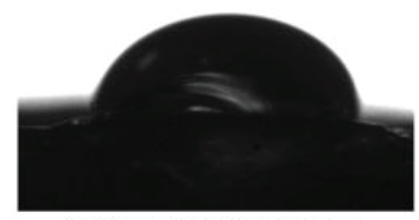

S-FPU $-100-15-1530-1: 2$
Fig 4. The contact angle test of S-FPU 
Table. 3 The contact angle and surface fluorine element content of S-FPU

\begin{tabular}{cccc}
\hline samples & curing temperature $\left({ }^{\circ} \mathrm{C}\right)$ & contact angle $\left({ }^{\circ}\right)$ & $\begin{array}{c}\text { surface fluorine element content } \\
(\%)\end{array}$ \\
\hline S-FPU $_{3}-40-15-1530-1: 2$ & & 97.1 & 8.54 \\
S-FPU $_{3}-60-15-1530-1: 2$ & 60 & 92.3 & 6.88 \\
S-FPU $_{3}-80-15-1530-1: 2$ & 80 & 88.5 & 5.25 \\
S-FPU $_{3}-100-15-1530-1: 2$ & 100 & 85.3 & 4.30 \\
\hline
\end{tabular}

\section{Conclusion}

In Summary, we presented a new synthetic method of S-FPU by cationic copolymerization of THF with the FO and studied the surface properties of S-FPU. In this paper, we concluded that lower curing temperature was advantaged for the migration of fluorine element to the surface. After the formation of the three-dimensional network structure, it was hard for the fluorine-containing side segments to move to the surface. However, when the molecular weight increased, the flexibility of soft segment was improved so that it was easier for the side chains which contains fluorine to transfer to the surface. On one hand, the space steric hindrance was strong, which hindered the side chains to transfer to the surface, so the surface fluorine content became lower. On the other hand, the noumenal fluorine content was lower, the surface fluorine content was lower too. The surface hydrophobic would be better, if the surface fluorine content increased.

\section{Acknowledgments}

This work was supported by the National Natural Science Foundation of China (21101107, 51373100, 51173107, 5140030478), the innovation Project of the Shanghai Municipal Education Commission(No.15ZZ076), and the Hujiang Foundation of China(B14006).

\section{References}

1. Sheng, Y. P., Jiang,P.P., Zhang,D.Y., Journal of Applied Polymer Science. 2015, 132(2).41277.

2. Zheng, Z. J, Yu. Q, F. He, L. H, Ye, G. C, Xu, W. X, Liao, J. L, Liu, Y. Chem. Eng. J.2013, (5).810.

3. Zheng, F. L., Xiang, S. L., Lu, C. H., Zhao, S. L., Xu, Z. Z. PaintCoating Industry, 2009, 39(7).45.

4. Zhang, F. C., Yang, J. J., Wu, M. Y., Wu, Q. Y., Zhang, J. A. New Chem. Mater.2011, 39(7).25.

5. Wang,S.J., Liu,W.Q., Tan,J.Q., Journal of Macromolecular Science, Part A: Pure and Applied Chemistry. 2016, 53(1):41.

6. A. Frick, A. Rochman, Polym. Test. 2004,23 (4). 413.

7. M. Rogulska, W. Podkoscielny, A. Kultys, S. Pikus, E. Pozdzik, Eur. Polym. J. 2006,42 (8). 1786.

8. H. Yeganeh, M. Barikani, F.N. Khodabadi, Eur. Polym. J. 2000,36 (10).2207.

9. Cao, Q., Li, Y., Jing, B., Liu, P.S., J. Appl. Polym. Sci. 2006, 102 (6).5266.

10. T.M. Chapman,R. Benrashid,K. G.Marra,J.P.Keener,.Macromolecules.1995,28,331.
11. Tonelli, C. and Ajroldi, G.J. J. Appl. Polym. Sci. 2003, 87(14). 2279.

12. Zhao,X.W., Ding,J.J., Ye,L., Journal of Fluorine Chemistry.2014, 159,38..

13. Lahiouhel, D.Ameduri, B.Boutevin, B. J. FluorineChem.,2001,107, 81.

14. T. Liu, L. Ye, J. Fluorine Chem. 2010, 36, 131.

15. Lee MH, Jang MK, Kim BK. Eur Polym J .2007, 43(10), 4271 .

16. Jeong HY, Lee MH, Kim BK. Colloid Surface A. 2006, 290(1-3), 178.

17. Wang,X., Hu,J.J., Li,Y., Zhang,J.R., Ding, Y.Y., Journal of Fluorine Chemistry. 2015, 176:14.

18. Wang,X.,Xu,J.C.,Li,L.L.,Liu,Y.,Li,Y.,Dong,Q.Z., Polymer.2016,98,311 